\title{
Osseointegration evaluation of ZrTi alloys with hydroxyapatite-zirconia-silver layer in pig's tibiae
}

Lucia Carmen Trincă ${ }^{1, *}$, Daniel Mareci ${ }^{2}$, Ricardo Manuel Souto ${ }^{3,4, *}$, Antonio Diego

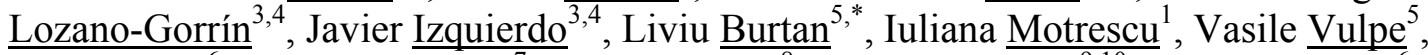
Geta Pavel $^{6}$, Stefan $\underline{\text { Strungaru }}^{7}$, Iulian Stoleriu ${ }^{8}$, Aurel Lulu $\underline{\text { Strat }}^{9,10}$, Carmen $\underline{\text { Solcan }}{ }^{6}$

1 Exact Sciences Department, "Ion Ionescu de la Brad" University of Agricultural Sciences and Veterinary Medicine, Faculty of Horticulture, Str. Aleea M. Sadoveanu, no. 3, 700490, Iasi, Romania.

2 Department of Chemical Engineering, Technical University "Gheorghe Asachi” of Iasi, Faculty of Chemical Engineering and Environmental Protection, D. Mangeron, Iasi, 700050, Romania.

${ }^{3}$ Department of Chemistry, Universidad de La Laguna, E-38200 La Laguna (Tenerife, Canary Islands), Spain.

${ }^{4}$ Institute of Material Science and Nanotechnology, Universidad de La Laguna, E-38200 La Laguna (Tenerife, Canary Islands), Spain.

${ }^{5}$ Clinics Department, "Ion Ionescu de la Brad" University of Agricultural Sciences and Veterinary Medicine, Faculty of Veterinary Medicine, Str. Aleea M. Sadoveanu, no. 8, 700489, Iasi, Romania.

${ }^{6}$ Preclinics Department,"Ion Ionescu de la Brad" University of Agricultural Sciences and Veterinary Medicine, Faculty of Veterinary Medicine, Str. Aleea M. Sadoveanu, no. 8, 700489, Iasi, Romania.

7 Department of Research, "Alexandru Ioan Cuza" University of Iasi, , Faculty of Biology, Bd. Carol I, 20A, 700505, Iasi, Romania.

${ }^{8}$ Faculty of Mathematics, "Alexandru Ioan Cuza" University of Iasi, Bd. Carol I, No. 11, 700506 Iasi, Romania.

9 Department of Pharmacology, Faculty of Medicine, "Grigore T. Popa" University of Medicine and Pharmacy, 16, University Street, 700115, Iasi, Romania.

10 Laboratory of Microbiology, Hospital of Infectious Diseases "Saint Parascheva", 2, OctavBotez Street, 700116 Iasi, Romania

doi: $10.1016 / \mathrm{j}$. apsusc.2019.05.003 


\begin{abstract}
:
In this work we studied the main surface characteristics together with the in vivo osseointegration of three $\mathrm{Zr}$ - Ti alloys with hydroxyapatite-zirconia-silver $\left(\mathrm{HAP}-\mathrm{ZrO}_{2}-\right.$ Ag) coating layer. The main purpose was to provide a quantitative evaluation and interpretation from micro to nano scale of the processes involved in the osseointegration of the HAP-Z $\mathrm{rO}_{2}-\mathrm{Ag}$ coated $\mathrm{Zr}-\mathrm{Ti}$ specimens in a pig model. The surface characteristics were studied by scanning electron microscopy (SEM), energy dispersive X-ray spectroscopy (EDX), and X-ray diffraction (XRD). After the insertion of the implants into pig tibia, the osseointegration was investigated by means of biochemical analysis as well as bone histomorphometric and computed tomography measurements. The results of this in vivo study sustains that the capacity of the Zr-Ti specimens coated with HAP$\mathrm{ZrO}_{2}-\mathrm{Ag}$ to promote osteogenesis is significant during the first month after implantation as compared with the control, being influenced by the interactions between bone tissue and $\mathrm{HAP}-\mathrm{ZrO}_{2}-\mathrm{Ag}$ surfaces, but also by the chemical composition of the alloys.
\end{abstract}

Keywords: osseointegration; hydroxyapatite; zirconia; silver; $\mathrm{Zr}$-Ti alloys; coating layer.

\title{
Abbreviations:
}

$\mathrm{HAP}-\mathrm{ZrO}_{2}$-Ag: hydroxyapatite-zirconia-silver

ALP: alkaline phosphatase 


\section{Introduction}

In the last decade, several studies have reported on the potential application of $\mathrm{ZrTi}$ alloys as implant biomaterials due to their improved mechanical characteristics related to the amalgam's composition and structure [1-4], whereas other studies described their high corrosion resistance conferred by the combined effect of $\mathrm{TiO}_{2}$ and $\mathrm{ZrO}_{2}$ that jointly form the protective passive layers [5-17]. In contrast, only very few studies have attempted to characterize their biological activity either in vitro [18,19] or in vivo [20].

The optimal proportion between $\mathrm{Zr}$ and $\mathrm{Ti}$ is still being tested, since the ideal alloy candidate must combine mechanical properties similar with those occurring at the body's area where it will be implanted, a high resistance to localized corrosion, and an increased biological activity. Although the debate concerning the optimal alloy composition remains open, it is widely accepted that both the corrosion behavior and the osseointegration process into the bone tissue depend on the physicochemical characteristics of the implant surface [21,22]. Thus, a metallic implant presenting a coating layer with an optimized composition and structure would promote an enhanced osseointegration.

The main objective of this study was to approach a multidisciplinary investigation focused on the osseointegration characteristics of a series of ZrTi alloys (namely, Zr5Ti, $\mathrm{Zr} 25 \mathrm{Ti}$, and $\mathrm{Zr} 45 \mathrm{Ti})$ coated with a hydroxyapatite-zirconia-silver ( $\left.\mathrm{HAP}-\mathrm{ZrO}_{2}-\mathrm{Ag}\right)$ layer in vivo. Hydroxyapatite (HAP) has a similar mineral constitution as the bone, thus favoring host-tissue responses and enhancing its fixation to hard bone. HAP composites with zirconia $\left(\mathrm{ZrO}_{2}\right)$ can upgrade the low bonding strength induced by the mismatch of thermal expansion coefficients between porous hydroxyapatite and the main alloy components. Zirconia has also demonstrated superior ability to induce bone formation in biological environments [23-26]. Finally, silver can inhibit bacterial growth, thus reducing the eventuality of infections resulting from surgical procedures, but also might improve mineral deposition, and expression of osteogenic markers [27,28]. We investigated osseointegration by means of biochemical analysis as well as by bone histomorphometrically and computed tomography measurements, after insertion of the $\mathrm{HAP}-\mathrm{ZrO}_{2}-\mathrm{Ag}$ coated $\mathrm{ZrTi}$ specimens in the pig's tibia. Our goal was to attain a better 
understanding of the $\mathrm{HAP}-\mathrm{ZrO} \mathrm{r}_{2}-\mathrm{Ag}$ surface layer biotransformation within the regenerating tissue and its impact on bone formation, as well as to determine if there is an optimal proportion of $\mathrm{Zr}$ and $\mathrm{Ti}$ concentrations in the binary alloy with respect to corrosion resistance and osseointegration.

\section{Materials and Methods}

\subsection{Materials}

Three ZrTi alloys fabricated by a multiple electron beam drip melting method were used as primary substrates. The chemical compositions of the alloys are given in Table 1. Cylindrical ingot samples with $8 \mathrm{~mm}$ diameter and $8 \mathrm{~mm}$ height were ground to a 2000 grit, finished with silicon carbide paper, ultrasonically cleaned in distilled water, degreased in ethanol, and dried in air. The samples were next oxidized in air at $500{ }^{\circ} \mathrm{C}$ for $4 \mathrm{~h}$, as described in detail elsewhere [12].

$\mathrm{HAP}-\mathrm{ZrO}_{2}-\mathrm{Ag}$ nanoparticles were generated by ultrasonic irradiation (Sonopuls HD 3200 reactor, Bandelin, Berlin, Germany). The HAP- $\mathrm{ZrO}_{2}-\mathrm{Ag}$ solution was calcined at $675^{\circ} \mathrm{C}$ to prepare a crystalline target surface. Plasma laser deposition was performed in a vacuum chamber with HAP (Zr, Ag doped) target using a Nd-YAG laser with a fluence of $5 \mathrm{~J} / \mathrm{cm}^{2}$, as presented elsewhere [14]

\subsection{Microstructural characterization}

Morphological characterization of the samples was performed by scanning electron microscopy (SEM) using a VEGA II LMH SEM (Tescan, Brno, Czech Republic) equipped with energy-dispersive X-ray spectroscopy (EDX) analysis (model XFlash, Bruker, Billerica, MA, USA). The mean diameter of the particles and size distribution in the deposited surface layer were analyzed by laser light diffraction with a Shimadzu SALD-7001 (Kyoto, Japan). MATLAB® Software [29] was used for 2D and $3 \mathrm{D}$ reconstruction of the images of the plot surface profiles.

X-ray diffraction (XRD) analysis was performed to identify the composition and microstructure of the samples retrieved from the animal models. XRD spectra were recorded using a PANalytical X'Pert PRO MRD (Almelo, The Netherlands) 
diffractometer equipped with a $\mathrm{Cu} \mathrm{K} \alpha$ anode. The XRD patterns were scanned in the range $20 \leq^{\circ} 2 \theta \leq 80$ at a rate of $1.8^{\circ} \mathrm{min}^{-1}$.

\subsection{Evaluation of in vivo osseointegration}

Implantation was surgically performed on the left tibial crest of the anesthetized animals following the procedure schematically shown in Figure 1. Each of the three implant materials (Zr5Ti, Zr25Ti, Zr45Ti) and one control implant (AISI 316L stainless steel) of cylindrical shape with dimensions of $0.8 \mathrm{~cm} \times 0.8 \mathrm{~cm}$ were implanted in the tibial crest of male pigs (3 months old, approximate weight $21 \mathrm{~kg}$ ). During the experiment, the animals were housed with free access to food and water according to standard ISO 10993-2:2006 on animal welfare [30]. The experimental model was conducted for a month. The dynamic evaluation consisted in clinical observations, radiological investigations, and biochemical tests on blood samples collected every 7 days. Also, histopathological and computed tomography investigations have been performed on tibia bone samples, harvested at the end of the experimental period.

\subsubsection{Biochemical analysis}

Blood samples were collected from the auricular vein under anesthetic condition every seven days during one month after the implantation procedure. Analysis were performed at the clinical and biochemical laboratory in the Faculty of Veterinary Medicine, Iasi. Serum was separated by centrifugation and inorganic phosphate $\left(\mathrm{PO}_{4}{ }^{3-}\right)$, ionic calcium $\left(\mathrm{Ca}^{2+}\right)$, alkaline phospatase (ALP), and total proteins (TP) were spectrophotometrically determined using BS-130 Biochem Automatic Analyzer and Liquick Cor-PZ kit tests (Cormay, Łomianki, Poland).

Calcium from bone was measured with a flame air-acetylene atomic absorption spectrometer model GBC Avanta (GBC Scientific Equipment, Braeside, VIC, Australia). Silver and phosphorous were measured with a high-resolution continuum source and a graphite furnace with platform model ContrAA 600 (Analytik Jena, Jena, Germany) equipped with MPE 60 autosampler. Argon 5.0 (99.99\%) was used as carrier gas. All the samples were prepared before. Pure reagents were used for the sample's digestion: nitric acid of high purity $65 \%$ and hydrogen peroxide EMSURE $30 \%$ 
stabilized for higher storage temperature, both supplied by Merck (Darmstadt, Germany). The calibration was done with certificated standards stock solutions (1000 $\left.\mathrm{mg} \mathrm{L}^{-1}\right)$ from Merck that were diluted with ultrapure acidified water $\left(0.5 \% \mathrm{HNO}_{3}\right)$.

\subsubsection{Histomorphometric analysis}

At the end of the experimental period, the callus along with normal bone were collected from the fracture site. The samples were cut into small pieces and stored in $10 \%$ formalin solution for three days, demineralized with 10\% EDTA, dehydrated in ascending grades of alcohol and embedded in paraffin. Five to six micrometer thick sections of the area close to the defect site were cut and prepared for staining with hematoxylin and eosin (i.e., H\&E staining method) for histological studies. The stained sections were examined under light microscope using $100-1000 \times$ magnifications. Bone on-growth at the implant surface as well as the number of normal and activated macrophages were quantified by static histomorphometry [31]. Each zone was evaluated in three independent counting sessions by two trained observers.

\subsubsection{Computed tomography analysis}

A high-resolution CT system (X-ray CT, Siemens Somatom, Balance, Erlangen, Germany) was employed to evaluate the microstructure of each pig's left back member, with a scanning resolution of $20 \mu \mathrm{m} / \mathrm{slice}$. After scanning, 3-D images were reconstructed based on the acquired 2-D image sequences using Syngo viewer software, Version 2.21. The systematic variation in the bone architecture inside the bone was analyzed based on the number of voxels present in a partitular range of Hounsfeld Units (HU). The trabecular bone parameters, including bone volume per tissue volume (BV/TV), trabecular thickness (Tb.Th), and trabecular separation (Tb.Sp) were quantified using ImageJ and BoneJ softwares [32]. The region of interest was defined as a rectangle that circumscribed the implant surface (embedded in a tangent way the implant surface).

\subsubsection{Statistical analysis}

Statistical analysis were performed using IBM SPSS Statistics for Windows Version 21.0 [33]. All data were examined for normal distribution using Shapiro Wilks 
test. For all in vivo results, the differences between the experimental groups were examined using Mann-Whitney U Test, considering $p<0.05$ as statistically significant difference.

\section{Results and Discussion}

\subsection{Microstructural characterization of $\mathrm{ZrTi}$ implants with $\mathrm{HAP}-\mathrm{ZrO}_{2}-\mathrm{Ag}$ coating} layer

Combined SEM-EDX mapping was employed to characterize the morphology of the $\mathrm{ZrTi}$ alloys with the $\mathrm{HAP}-\mathrm{ZrO}_{2}-\mathrm{Ag}$ layer both prior and after animal tests. Figure 2 shows the occurrence of round nanoparticles $(70 \mathrm{~nm}$ diameter according to the size distribution profile) of $\mathrm{Ca}, \mathrm{P}, \mathrm{Zr}$, and $\mathrm{Ag}$ in the $\mathrm{HAP}-\mathrm{ZrO}_{2}-\mathrm{Ag}$ layer deposited on the surface of the ZrTi alloys prior to implantation.

On the other hand, Figure 3 summarises the SEM micrographs as well as 2D and $3 \mathrm{D}$ reconstructed images retrieved from the pig's tibiae at the end of the testing period. A first look reveals different morphological characteristics among the samples at this stage. Indeed, the SEM images revealed that the $\mathrm{ZrTi}$ specimens with the $\mathrm{HAP}-\mathrm{ZrO}_{2}-\mathrm{Ag}$ coated layer exhibited various degrees of defective morphology after implantation, as main signs of the biodegradation process they experienced in the physiological environment. Twodimensional (2D) reconstructed images allowed surface topography profiles of the HAP$\mathrm{ZrO}_{2}-\mathrm{Ag}$ layers deposited on the $\mathrm{Zr}-\mathrm{Ti}$ specimens to be extracted. A comparative analysis indicated that the $\mathrm{Zr} 45 \mathrm{Ti}$ specimen maintained a greater portion of the initial structure of the $\mathrm{HAP}-\mathrm{ZrO}_{2}-\mathrm{Ag}$ layer, with homogeneously distributed grains and droplets (that are characteristic for the medium pressure plasma laser deposits) with dimensions varying between hundreds of $\mathrm{nm}$ and 5-7 $\mu \mathrm{m}$ (cf. Table 2). Conversely, the Zr25Ti specimen preserved the lowest proportion of the $\mathrm{HAP}-\mathrm{ZrO}_{2}-\mathrm{Ag}$ layer initial structure. Nevertheless, the highest values of the average roughness and root-mean-square roughness, showing the closely spaced irregularities that would assure a better osseointegration process [3436], were monitored in the case of $\mathrm{HAP}-\mathrm{ZrO}_{2}-\mathrm{Ag}$ coated $\mathrm{Zr} 45 \mathrm{Ti}$ specimen, in good accordance with our previous reports [14].

According to EDX analysis (cf. Figure 4A) P, Zr, Ag, Ca, and Ti oxides together with their mixtures remained stable constituents after the implantation period, as their 
presence was spotted even after cleaning by ultrasonication of the $\mathrm{ZrTi}+\mathrm{HAP}-\mathrm{ZrO}_{2}-\mathrm{Ag}$ specimens harvested after implantation period. Table 3 presents the chemical analysis of the implant surfaces determined by EDX. The great variability of the chemical composition after implantation can be explained by considering both the reactions involved in the biodegradation process of the $\mathrm{HAP}-\mathrm{ZrO}{ }_{2}-\mathrm{Ag}$ coated $\mathrm{Zr}$ - Ti samples, as well as the interactions between the implanted specimen and the main blood components. Thus, the decrease of the $\mathrm{Zr}$ concentration due to the degradation of the $\mathrm{HAP}-\mathrm{ZrO} \mathrm{rag}_{2}-\mathrm{Ag}$ surface layer explains the relative increase of $\mathrm{Ti}$ concentration. The lower $\mathrm{Ag}$ concentration sustains a more intensive biodegradation process of the $\mathrm{HAP}-\mathrm{ZrO}_{2}-\mathrm{Ag}$ surface layer in the case of the Zr25Ti specimen. The increased P concentration induced a different $\mathrm{Ca} / \mathrm{P}$ ratio that can be explained by a slower biodegradation of the $\mathrm{HAP}-\mathrm{ZrO}_{2}-$ Ag layer, in the case of Zr45Ti alloy. Also, the increased concentration of oxygen in the case of Zr5Ti and Zr25Ti samples supports a less intense biodegradation process of the $\mathrm{HAP}-\mathrm{ZrO}_{2}-\mathrm{Ag}$ layer for the $\mathrm{Zr} 45 \mathrm{Ti}$ specimen.

Further characterization of the $\mathrm{ZrTi}$ specimens with $\mathrm{HAP}-\mathrm{ZrO}_{2}-\mathrm{Ag}$ layer (after implantation and cleaning by ultrasonication) was performed from the XRD data shown in Figure 4B. Phase identification was performed by matching each peak with JCPDSICDD files (01-072-3354, 04-003-1466 and 01-077-3484) confirming the presence of both $\mathrm{TiO}_{2}$ and $\mathrm{ZrO}_{2}$ derived from the oxidation of the original $\mathrm{ZrTi}$ alloys, thus confirming $\mathrm{Ti}$ and $\mathrm{Zr}$ as the only bulk components of the original alloys. The systematic displacement of the peaks to higher angles $\left({ }^{\circ} 2 \theta\right)$ with the increasing Ti content in the alloy is indicative that the atomic radius of $\mathrm{Ti}$ is smaller than that of $\mathrm{Zr}$ by taking into account the Bragg's law $(\lambda=2 d \sin \theta)$ where the interplanar spacing $d$ in the structure and the Bragg's angle $\theta$ are inversely proportional. In effect, the atomic radii of titanium and zirconium are 176 and 206 pm, respectively.

\subsection{Osseointegration evaluation}

\subsubsection{Biochemical analysis}


The main blood biochemical parameters under investigation showed statistically insignificant variations $(p>0.05)$ for any pairs of two experimental groups considered (see Figure 5). This finding suggests a similar response mechanism of the pig's organism for all implanted specimens during the tibial bone restoration period after the implantation surgery.

In the case of a growing organism, the activity of serum alkaline phospatase is mainly due to the bone isoenzyme [37], which explains the positive correlations between alkaline phosphatase activity and phospho-calcic metabolism variations involved in the bone fracture repair. Thus, if in the first seven days from the implantation, the calcemia and phosphatemia variations were determined by the metabolic disorders induced by the surgical stress [38], in the next 7-21 days, the phosho-calcic variations were influenced by the higher values of alkaline phosphatase activity due to the significant activation of osteoblasts, as a normal stage of bone fracture repair [39]. Hypocalcaemia and hypophosphatemia recorded between 21 and 28 days have been associated with the formation of calcium phosphate deposits and the subsequent transformation of osteoblasts into osteoclast [40-42], once with their catching by the extracellular mineralized matrix.

In our experimental model, the alkaline phosphatase (ALP) activity variation was consistent with the enzyme's activity pattern reported for the tibia fracture [43]. Furthermore, in the case of the $\mathrm{Zr} 45 \mathrm{Ti}$ implant with $\mathrm{HAP}-\mathrm{ZrO}_{2}-\mathrm{Ag}$ layer, the negative and positive variations of the ALP amplitude were relatively similar without being significantly different; on the twenty-eight day after the implantation both the alkaline phosphatase activity and the $\mathrm{Ca} / \mathrm{P}$ ratio came close to normal values, thus ensuring optimum conditions for the normal fracture repair.

Table 4 presents the Ag concentration of the bone surface in close contact with the implant evaluated in order to provide a sensitive measure of biodegradation process of the HAP-ZrO $2-\mathrm{Ag}$ coated layer of the $\mathrm{ZrTi}$ specimens, and the evaluation of $\mathrm{Ca} / \mathrm{P}$ ratios, to evaluate the bone mineral changes. Analysis of the bone $\mathrm{Ca}$ and $\mathrm{P}$ concentrations indicated a reciprocal correlation between the $\mathrm{Ca} / \mathrm{P}$ ratio and the newly formed bone volume, in good accordance with previous reports [44]. In addition, a significant $(p<0.001)$ biodegradation was registered in the case of the $\mathrm{HAP}-\mathrm{ZrO}_{2}-\mathrm{Ag}$ layer on the $\mathrm{Zr} 25 \mathrm{Ti}$ alloy. The migration of $\mathrm{Ag}$ from the $\mathrm{HAP}-\mathrm{ZrO}_{2}-\mathrm{Ag}$ coated layer was 
much easier and registered a significant higher Ag concentation in the bone tissue in close contact with the implant in the case of the $\mathrm{Zr25Ti}$ group, which highlights a significant biodegradation process.

\subsubsection{Morpho-histometry of bone tissue at the contact interface with the implanted} specimens

Histological investigations revealed the main morphology of the bone tissue area in direct contact with the implant as well as the implant's proximity area as shown in Figure 6. For all ZrTi implanted specimens newly bony ingrowth was evident after one month of healing. and followed the main stages of the normal bone recovery process $[23,45-47]$. The newly formed bone tissue was produced due the intense activity of the cuboid-shaped osteoblasts, with diameters of 12-14 $\mu \mathrm{m}$, oriented on 3-6 rows. Newly formed bone bays contained empty lacunae as well as occupied lacunae with metabolically active large osteocytes presenting preeminent extensions. In areoles a large network of reticulin fibers, numerous capillaries, and many osteoprogenitor cells can be observed.

In the implant proximity area $(<2500 \mu \mathrm{m})$, bone bays show lacunae occupied by metabolically active osteocytes. Near the bone matrix, oriented osteoblasts aligned on a decreasing number of rows once it increases the distance from implant can be observed. The presence of the macrophages in the neighborhood area (i.e., around 2500-6000 $\mu \mathrm{m}$ ) of the implant, in the bone areoles outside the reticulin fibers, capillaries and osteoprogenitor cells, signals an inflammation state [48] as a normal stage of tissue regeneration. In the adjacent tissue from the implant vicinity, the histological investigations revealed the existence of some acicular brown pigmentated products, fagocited by the macrophages that have most probably been structural conglomerates migrated from the implant surface once its structure was affected either by the frictional stress, or by the electrochemical potential difference.

The elemental nanoscale mapping by EDX of the bone-implant interface given in Figure 7 showed that in the case of ZrTi specimens, $\mathrm{Zr}$ was present in the new bone tissue, being colocalized with $\mathrm{C}$ and $\mathrm{P}$, respectively, but also in the acicular brown debris phagocytized by the macrophages. No presence of Ag could be detected in this case, most 
likely due to the prior histological processing of the samples that reduced its concentration below the detection limit of the EDX.

In general, when metal particles/ions are released from the implant surface, they might either systemically migrate, remain in the intercellular spaces near the site where they were released, or they are taken up by macrophages, considered as the major modulators of the biomaterial's integration into the tissue. The number of normal macrophages as well as the number of the loaded macrophages with debris from the implant's surface are presented in Table 5. According to these data, the statistically insignificant difference $(p>0.05)$ of the macrophage total number highlights a similar inflammatory response in the case of $\mathrm{HAP}-\mathrm{ZrO}_{2}-\mathrm{Ag}$ coated $\mathrm{Zr} 45 \mathrm{Ti}$ and $\mathrm{Zr} 5 \mathrm{Ti}$ implants one month after implantation, while the significant statistically increase $(p<0.01)$ of the macrophage total number sustains a more intense inflammatory response in the case of the HAP- $\mathrm{ZrO}_{2}-\mathrm{Ag}$ coated $\mathrm{Zr} 25 \mathrm{Ti}$ implant. This is also found in the case of the Control group, indicating the induction of a chronic inflammatory state one month after implantation in both cases. In addition, the ratios of macrophages loaded with debris from the implant surface with respect to free macrophages were similar for both $\mathrm{HAP}-\mathrm{ZrO} \mathrm{O}_{2}-\mathrm{Ag}$ coating layers of the Zr5Ti and Zr45Ti alloys (0.392 and 0.367 , respectively), whereas a significantly higher value of 2.125 was derived for the HAP- $\mathrm{ZrO}_{2}-\mathrm{Ag}$ coated layer of the Zr25Ti alloy. These observations suggest a more intensive biodegradation process of the $\mathrm{HAP}-\mathrm{ZrO}_{2}$-Ag coated layer covering the $\mathrm{Zr} 25 \mathrm{Ti}$ alloy surface.

Macrophages are the major modulators of biomaterial integration, being able of polarizing from contributors of the tissue inflammation (M1 phenotype) toward contributors of wound healing (M2 phenotype). Surface nano-topography, particle size, porosity, and the released ions from the biomaterials might induce distinct macrophage phenotype response both in vitro and in vivo, that might be closely related to the osseointegration outcomes [49-51]. However, detailed information such as the mutual interaction between macrophages and bone marrow mesenchymal stem cells and the association between macrophage activation and osseointegration requires further solid evidences. Anyhow, a balanced activation of the macrophages, as recorded in the case of $\mathrm{HAP}-\mathrm{ZrO}_{2}-\mathrm{Ag}$ coated layer of the $\mathrm{Zr} 45 \mathrm{Ti}$ alloy, with a subsequent versatile macrophage polarization towards M1 and M2 phenotypes, represents an important step for 
establishing the equilibrium between osteogenic factors/cells and osteolytic factors/cells around implant after osseointegration [52]. Macrophages phenotype differentiation/polarization and their persistence in the response to the $\mathrm{HAP}-\mathrm{ZrO}_{2}-\mathrm{Ag}$ coated layer of the ZrTi alloys, will be investigated in future studies because it requires a special prior preparation of bone tissue samples.

White blood cells counting (cf. Table S-1 in the Supplementary material) pointed out that in the case of control group, the high ratio of loaded/free macrophages (namely, 1.833) might be associated with an inflammatory resolutive lympho-histiocytic inflammation subsequent to a fibrous encapsulation. The Zr45Ti group showed reduced macrophage distribution and less inflammation related with the state of convalescence. The systemic reactivity based on the quantitative changes in the leukocyte cellular blood cells of the Zr5Ti group was more similar to those of the Zr45Ti group while, the systemic reactivity for the $\mathrm{Zr} 25 \mathrm{Ti}$ group was more similar to that of the control group.

\subsubsection{CT analysis of the in vivo osseointegration of the implanted specimens}

The computed tomography images of the pig's tibiae bone with the implant displayed in Figure 8 highlight the integration of the implant in the tibia's bone tissue, by pointing out the aspect of the newly formed bone tissue deposited on the implant surface and around the implant. They showed that integration of the ZrTi implants coated with $\mathrm{HAP}-\mathrm{ZrO}_{2}-\mathrm{Ag}$ layer to the tibial bone was achieved mainly through contact osteogenesis, as the newly formed bone developed from the implant surface to the healing bone [53].

BV/TV, Tb.Th (mm), and Tb.Sp (mm) were determined with BoneJ software and they are plotted in Figure 9. The primary region of interest was defined as a rectangle, circumscribing the implant surface. Next, the variation of these parameters with the distance, was evaluated in size increments of the region of interest by adding 2.5 , $5,7.5$, and $10 \mathrm{~mm}$ (both in length and width) to the primary region of interest.

The 2D-CT and 3D-CT reconstructed images of Figure 8 allowed the primary evaluation of the osseo-conduction process by measuring the new bone tissue compact area covering the implanted sample, namely $77.8 \mathrm{~mm}^{2}$ for $\mathrm{Zr} 5 \mathrm{Ti}, 62.49 \mathrm{~mm}^{2}$ for $\mathrm{Zr} 25 \mathrm{Ti}$, $78.6 \mathrm{~mm}^{2}$ for $\mathrm{Zr} 45 \mathrm{Ti}$, and $48.54 \mathrm{~mm}^{2}$ for the control, respectively. Figure 9 also gives the values of $\mathrm{BV} / \mathrm{TV}$ and $\mathrm{Tb}$.Th, two specific bone trabecular parameters, and they support 
that all three $\mathrm{ZrTi}$ specimens with the $\mathrm{HAP}-\mathrm{ZrO}_{2}-\mathrm{Ag}$ coated layer presented statistically significant higher osseoconduction $(p<0.05)$ when compared with the control sample. A comparison between the three ZrTi specimens reveals a statistically significant more intense osseoconduction process $(p<0.05)$ in the case of $\mathrm{Zr} 45 \mathrm{Ti}$ and $\mathrm{Zr} 25 \mathrm{Ti}$ compared with $\mathrm{Zr} 5 \mathrm{Ti}$, which evidences a inverse relationship between the osteoconduction and the biodegradation processes, in good agreement with the conclusions of our previous in vitro study based on corrosion resistance measurements [14]. The different behavior of the $\mathrm{HAP}-\mathrm{ZrO}_{2}-\mathrm{Ag}$ coated $\mathrm{Zr} 5 \mathrm{Ti}$ specimen, which registered the greatest values for the trabecular space, and the smallest compact area among the three ZrTi specimens, are directly related to the extent of the biodegradation process as revealed by the surface characterization of the samples after implantation and by the biochemical investigation of the newly formed bone tissue together with the morpho-histometric evaluation of the macrophages loaded with debris from the implant surface. These results support the conclusion that the organizational structure of the newly formed bone tissue is affected by the interactions between the bone tissue and the surfaces of the implanted specimens, but also by the chemical composition of the bulk alloy.

In summary, the quantitative $\mathrm{CT}$ analysis of the newly bone tissue formed by contact osteogenesis in the first month after implantation indicated a higher osseointegration in the case of the $\mathrm{HAP}-\mathrm{ZrO}_{2}-\mathrm{Ag}$ coated $\mathrm{Zr} 45 \mathrm{Ti}$ specimen, as sustained by the the biggest new trabecular bone volume ratio, the increased thickness of the newly trabecular bone layer, as well as by the quite small trabecular space. A higher biodegradation of the $\mathrm{HAP}-\mathrm{ZrO}_{2}-\mathrm{Ag}$ surface layer induced a lower osseointegration with a reduced new trabecular bone volume ratio and trabecular thickness, and an extended trabecular space in the case of coated Zr25Ti specimen.

\section{Conclusions}

1. The current in vivo study sustains the capacity of the ZrTi implants coated with $\mathrm{HAP}-\mathrm{ZrO}_{2}-\mathrm{Ag}$ layers to promote osteogenesis was significant during the first month after implantation as compared with the control.

2. In the case of the $\mathrm{Zr} 45 \mathrm{Ti}$ specimen with a $\mathrm{HAP}-\mathrm{ZrO}_{2}-\mathrm{Ag}$ layer, a higher osteoconduction was observed, as the implanted sample was covered by a 
significant increased surface of the newly formed bone tissue layer with bigger trabecular thickness and lower trabecular space.

3. The bigger new bone formation with better organizational structure registered in the case of the $\mathrm{Zr} 45 \mathrm{Ti}$ specimen coated with a $\mathrm{HAP}-\mathrm{ZrO}-\mathrm{Ag}$ layer assured an enhanced proliferation and differentiation of the osteoblasts.

4. The osseointegration of the implanted specimens was influenced by their biodegradation process and the interactions between bone tissue and the HAP$\mathrm{ZrO}_{2}-\mathrm{Ag}$ surfaces, but also by the bulk chemical composition of the $\mathrm{ZrTi}$ alloys.

\section{Acknowledgments}

This work was supported partially by the Romanian National Authority for Scientific Research (CNCS-UEFISCDI, project No. PN-II-IDPCE-2011-3-0218), and by the Spanish Ministry of Economy and Competitiveness (MINECO, Madrid, Spain) and the European Regional Development Fund (project No. CTQ2016-80522-P).

\section{References}

1. H.C. Hsu, S.C. Wu, Y.C. Sung, W.F. Ho, The structure and mechanical properties of as-cast Zr-Ti alloys, Journal of Alloys and Compounds 488 (2009) 279-283.

2. S.X. Liang, L.X. Yin, Y.K. Zhou, X.J. Feng, M.Z. Ma, R.P. Liu, C.L. Tan, Abnormal martensitic transformation of high Zr-containing Ti alloys, Journal of Alloys and Compounds 615 (2014) 804-808.

3. Y.K. Zhou, S.X. Liang, R. Jing, X.J. Jiang, M.Z. Ma, C.L. Tan, R.P. Liu, Microstructure and tensile properties of hot-rolled Zr50-Ti50 binary alloy, Materials Science and Engineering A 621 (2015) 259-264.

4. W. He, J. Ma, Y. Zhang, H. Wen, Q. Liu, Effect of the annealing process on the microstructure and mechanical properties of multilayered $\mathrm{Zr} / \mathrm{Ti}$ composites, Materials Science and Engineering A 713 (2018) 214-222.

5. N.T. Oliveira, S.R. Biaggio, R.C. Rocha-Filho, N. Bocchi, Electrochemical studies on zirconium and its biocompatible alloys Ti-50Zr at.\% and $\mathrm{Zr}-2.5 \mathrm{Nb}$ wt. $\%$ in simulated physiologic media, Journal of Biomedical Materials Research A 74 (2005) 397-407. 
6. R. Chelariu, D. Mareci, C. Munteanu, Preliminary electrochemical testing of some $\mathrm{Zr}$-Ti alloys in $0.9 \% \mathrm{NaCl}$ solution, Materials and Corrosion 64 (2013) 585-591.

7. D. Mareci, D. Sutiman, R. Chelariu, F. Leon, S. Curteanu, Evaluation of the corrosion resistance of new ZrTi alloys by experiment and simulation with an adaptive instance-based regression model, Corrosion Science 73 (2013) 106-122.

8. G. Bolat, J. Izquierdo, J.J. Santana, D. Mareci, R.M. Souto, Electrochemical characterization of ZrTi alloys for biomedical applications, Electrochimica Acta 88 (2013) 447-456.

9. G. Bolat, J. Izquierdo, D. Mareci, D. Sutiman, R.M. Souto, Electrochemical characterization of ZrTi alloys for biomedical applications. Part 2: The effect of thermal oxidation, Electrochimica Acta 106 (2013) 432-439.

10. J. Izquierdo, G. Bolat, D. Mareci, C. Munteanu, S. González, R.M. Souto, Electrochemical behaviour of ZrTi alloys in artificial physiological solution simulating in vitro inflammatory conditions, Applied Surface Science 313 (2014) 259-266.

11. D. Mareci, G. Bolat, A. Cailean, J.J. Santana, J. Izquierdo, R.M. Souto, Effect of acidic fluoride solution on the corrosion resistance of $\mathrm{ZrTi}$ alloys for dental implant application, Corrosion Science 87 (2014) 334-343.

12. D. Mareci, G. Bolat, B. Istrate, C. Munteanu, A. Cailean, Effect of thermal oxidation on electrochemical corrosion behaviour of ZrTi alloys for dental applications, Materials and Corrosion 66 (2015) 1529-1535.

13. W.F. Cui, C.J. Shao, The improved corrosion resistance and anti-wear performance of Zr-xTi alloys by thermal oxidation treatment, Surface and Coatings 283 (2015) 101107.

14. D. Mareci, L.C. Trincă, D. Căilean, R.M. Souto, Corrosion resistance of ZrTi alloys with hydroxyapatite-zirconia-silver layer in simulated physiological solution containing proteins for biomaterial applications, Applied Surface Science 389 (2016) 1069-1075.

15. L.C. Trincă, D. Mareci, N. Cimpoeşu, M. Călin, T. Stan, Influence of hydrogen peroxide on the corrosion of thermally oxidized $\mathrm{ZrTi}$ alloys in phosphated-buffered saline solucion, Materials and Corrosion 67 (2016) 1088-1095. 
16. D. Mareci, G.D. Suditu, R. Chelariu, L.C. Trincă, Curteanu S. Prediction of corrosion resistance of some dental metallic materials applying artificial neural networks. Materials and Corrosion 67 (2016) 1213-1219.

17. T. Akimoto, T. Ueno, Y. Tsutsumi, H. Doi, T. Hanawa, N. Wakabayashi, Evaluation of corrosion resistance of implant-use $\mathrm{Ti}-\mathrm{Zr}$ binary alloys with a range of compositions, Journal of Biomedical Materials Research Part B: Applied Biomaterials 106 (2018) 73-79.

18. T.J. Lee, T. Ueno, N. Nomura, N. Wakabayashi, T. Hanawa, Titanium-zirconium binary alloy as dental implant material: Analysis of the influence of compositional change on mechanical properties and in vitro biologic response, International Journal of Oral \& Maxillofacial Implants 31(2016) 547-554.

19. D. Ionita, M. Vardaki, M.S. Stan, A. Dinischiotu, I. Demetrescu, Enhanced stability and in vitro cell response to a bioinspired coating on $\mathrm{Zr}$ alloy with increasing chitosan content, Journal of Bionic Engineering 14 (2017) 459-467.

20. Y. Ikarashi, K. Toyoda, E. Kobayashi, H. Doi, T. Yoneyama, H. Hamanaka, T. Tsuchiya, Improved biocompatibility of titanium-zirconium (Ti-Zr) alloy: Tissue reaction and sensitization to $\mathrm{Ti}-\mathrm{Zr}$ alloy compared with pure $\mathrm{Ti}$ and $\mathrm{Zr}$ in rat implantation study, Materials Transactions 46 (2005) 2260-2267.

21. M. Niinomi, M. Nakai, J. Hieda, Development of new metallic alloys for biomedical applications, Acta Biomaterialia 8 (2012) 3888-3903.

22. M.A. Gepreel, M. Niinomi, Biocompatibility of Ti-alloys for long-term implantation. Journal of the Mechanical Behavior of Biomedical Materials 20 (2013) 407-415.

23. N. Saulacic, D. Bosshardt, M. Bornstein, S. Berner, D. Buser, Bone apposition to a titanium-zirconium alloy implant, as compared to two other titanium-containing implants, European Cells \& Materials 23 (2012) 273-286.

24. B.A. Lee, H.J. Kim, Y.Z. Xuan, Y.J. Park, H.J. Chung, Y.J. Kim, Osteoblastic behavior to zirconium coating on Ti-6Al-4V alloy, The Journal of Advanced Prosthodontics 6 (2014) 512-520.

25. Y. Chen, S.I. Roohani-Esfahani, Z. Lu, H. Zreiqat, C.R. Dunstan, Zirconium ions upregulate the $\mathrm{BMP} / \mathrm{SMAD}$ signaling pathway and promote the proliferation and 
differentiation of human osteoblasts, PLOS ONE 10 (2015) e0113426. https://doi.org/10.1371/journal.pone.0113426.

26. Y. Zhang, A.J. Davenport, B. Burke, N. Vyas, O. Addison, Effect of Zr addition on the corrosion of $\mathrm{Ti}$ in acidic and reactive oxygen species (ROS)-containing environments, ACS Biomaterials Science \& Engineering 4 (2018) 1103-1111.

27. B.S. Atiyeh, M. Costagliola, S.N. Hayek, S.A. Dibo, Effect of silver on burn wound infection control and healing: review of the literatura, Burns 33(2007) 139-148.

28. G. Pradhaban, G.S. Kaliaraj, V. Vishwakarma, Antibacterial effects of silver-zirconia composite coatings using pulsed laser deposition onto 316L SS for bio implants. Progress in Biomaterials 3 (2014) 123-130.

29. MATLAB and Statistics Toolbox Release 2012b, The MathWorks, Inc., Natick, MA, 2012.

30. ISO 10993-2:2006, Biological evaluation of medical devices - Part 2: Animal welfare requirements, International Organization for Standardization, Geneve, 2006.

31. R.J. van't Hof, L. Rose, E. Bassonga, A. Daroszewska, Open source software for semi-automated histomorphometry of bone resorption and formation parameters. Bone 99 (2017) 69-79.

32. M. Doube, M.M. Kłosowski, I. Arganda-Carreras, F.P. Cordelières, R.P. Dougherty, J.S. Jackson, B. Schmid, J.R. Hutchinson, S.J. Shefelbine, BoneJ: Free and extensible bone image analysis in Imagen, Bone 47 (2010) 1076-1079.

33. IBM SPSS Statistics for Windows, Version 21.0., IBM Corp., Armonk, NY, USA, 2012.

34. R.K. Alla, K. Ginjupalli, N. Upadhya, M. Shammas, R.K. Ravi, R. Sekhar, Surface roughness of implants: A review, Trends in Biomaterials and Artificial Organs 25 (2011) 112-118.

35. S.A. Hacking, P. Boyraz, B.M. Powers, E. Sen-Gupta, W. Kucharski, C.A. Brown, E.P. Cook, Surface roughness enhances the osseointegration of titanium headposts in non-human primates. Journal of Neuroscience Methods 211 (2012) 237-244.

36. P. Kwaśniak, J. Pura, M. Zwolińska, P. Wieciński, H. Skarżyński, L. Olszewski, J. Marczak, H. Garbacz, K.J. Kurzydłowski, Laser and chemical surface modifications 
of titanium grade 2 for medical application, Applied Surface Science 336 (2015) 267273.

37. V. Kumar, K.D. Gill, To estimate the activity of alkaline phosphatase in serum. In: Basic Concepts in Clinical Biochemistry: A Practical Guide, Springer, Singapore, 2018, pp. 107-109.

38. C. Sousa, H. Abreu, C. Viegas, J. Azevedo, R. Reis, M. Gomes, I. Dias, Serum total and bone alkaline phosphatase and tartrate-resistant acid phosphatase activities for the assessment of bone fracture healing in dogs, Arquivo Brasileiro de Medicina Veterinária e Zootecnia 63 (2011) 1007-1011.

39. M.O. Coulibaly, D.L. Sietsema, T.A. Burgers, J. Mason, B. Williams, C.B. Jones, Recent advances in the use of serological bone formation markers to monitor callus development and fracture healing, Critical Reviews ${ }^{\mathrm{TM}}$ in Eukaryotic Gene Expression 20 (2010) 105-127.

40. S. Khoshniat, A. Bourgine, M. Julien, P. Weiss, J. Guicheux, L. Beck, The emergence of phosphate as a specific signaling molecule in bone and other cell types in mammals, Cellular and Molecular Life Sciences 68 (2011) 205-218.

41. M. Fântânariu, L.C. Trincă, C. Solcan, A. Trofin, Ş. Strungaru, E.V. Şindilar, G. Plăvan, S. Stanciu, A new Fe-Mn-Si alloplastic biomaterial as bone grafting material: In vivo study. Applied Surface Science 352 (2015) 129-139.

42. L.C. Trincă, M. Fântânariu, C. Solcan, A.E. Trofin, L. Burtan, D.M. Acatrinei, S. Stanciu, B. Istrate, C. Munteanu, In vivo degradation behavior and biological activity of some new $\mathrm{Mg}-\mathrm{Ca}$ alloys with concentration's gradient of $\mathrm{Si}$ for bone grafos, Applied Surface Science 352 (2015) 140-150.

43. A. Muljačić, R. Poljak-Guberina, J. Turčić, O. Živković, M. Guberina, B. Klaić, The changes of bone-specific alkaline phosphatase (BsALP) associated with callus formation and rate of bone healing, Croatica Chemica Acta 83(2010) 315-321.

44. H. Orimo, The mechanism of mineralization and the role of alkaline phosphatase in health and disease, Journal of Nippon Medical School 77 (2010) 4-12.

45. U. Kini, B.N. Nandeesh, Physiology of bone formation, remodeling, and metabolism. In: Radionuclide and Hybrid Bone Imaging, Springer, Berlin, 2012, pp. 29-57. 
46. E.D. Wróbel, M.A. Witkowska-Zimny, Tissue engineering of bone: the role of osteoblasts in osteogenesis and peri-implant bone healing, Engineering of Biomaterials 119 (2013) 2-7.

47. N. Sagar, A.K. Singh, M.K. Temgire, S. Vijayalakshmi, A. Dhawan, A. Kumar, N. Chattopadhyay, J.R. Bellare, 3D scaffold induces efficient bone repair: in vivo studies of ultra-structural architecture at the interface, RSC Advances 6 (2016) 93768-93776.

48. C.L. Salgado, L. Grenho, M.H. Fernandes, B.J. Colaço, F.J. Monteiro, Biodegradation, biocompatibility, and osteoconduction evaluation of collagennanohydroxyapatite cryogels for bone tissue regeneration, Journal of Biomedical Materials Research A 104 (2016) 57-70.

49. J. Kzhyshkowska, A. Gudima, V. Riabov, C. Dollinger, P. Lavalle, N.E. Vrana, Macrophage responses to implants: prospects for personalized medicine, Journal of Leukocyte Biology 98(2015) 953-962.

50. Z. Chen, T. Klein, R.Z. Murray, R. Crawford, J. Chang, C. Wu, Y. Xiao, Osteoimmunomodulation for the development of advanced bone biomaterials, Materials Today 19(2016) 304-321.

51. R.J. Miron, D.D. Bosshardt, OsteoMacs: Key players around bone biomaterials, Biomaterials 82 (2016) 1-9.

52. J. Wang, F. Meng, W. Song, J. Jin, Q. Ma, D. Fei, L. Fang, L. Chen, Q. Wang, Y. Zhang, Nanostructured titanium regulates osseointegration via influencing macrophage polarization in the osteogenic environment, International Journal of Nanomedicine 13 (2018) 4029-4043.

53. A.F. Mavrogenis, R. Dimitriou, J. Parvizi, G.C. Babis, Biology of implant osseointegration, Journal of Musculoskeletal and Neuronal Interactions 9 (2009) 61 71. 


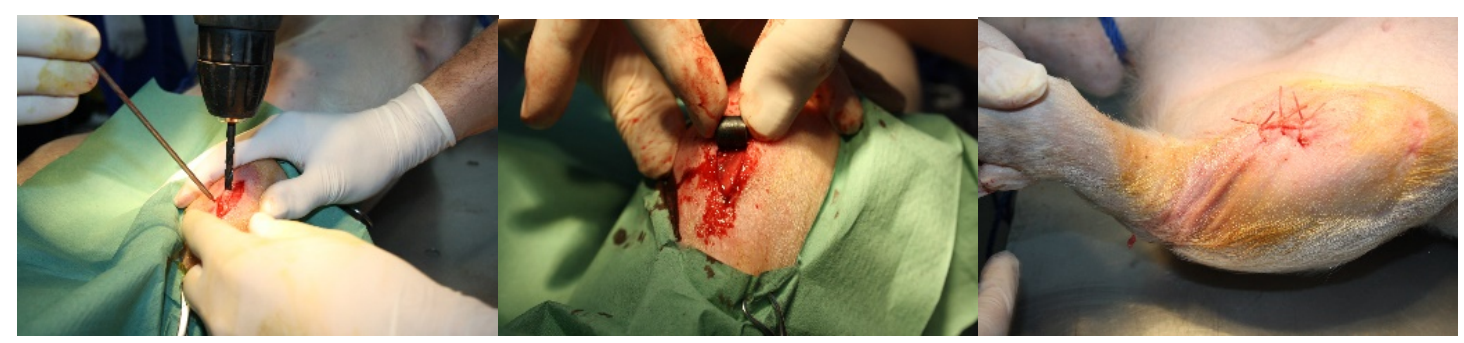

Figure 1. Main stages of the implant surgery in the tibia of a pig.

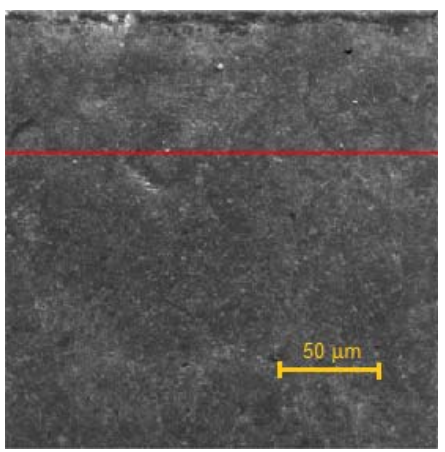

A

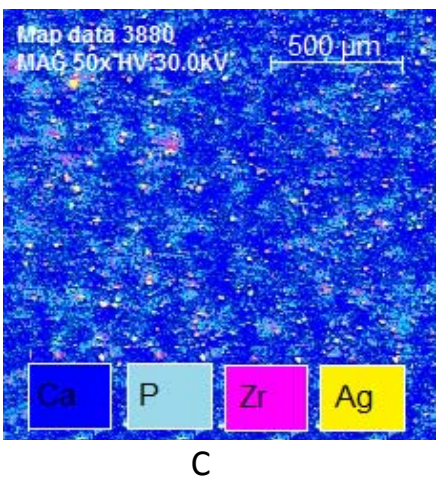

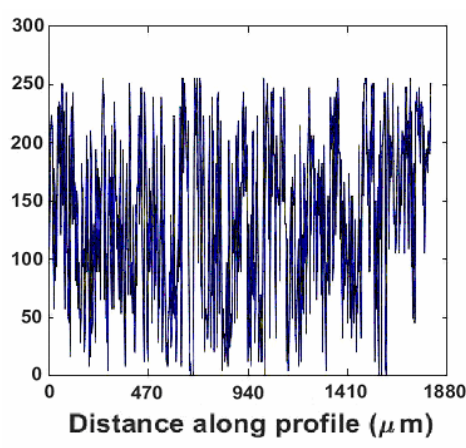

B

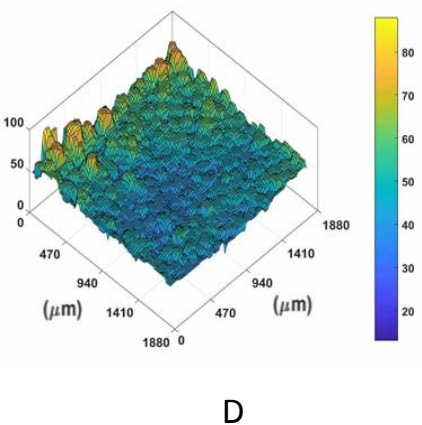

Figure 2. Characterization of the $\mathrm{HAP}-\mathrm{ZrO}_{2}-\mathrm{Ag}$ layer formed on the $\mathrm{ZrTi}$ alloy prior to implantation. (A) SEM image, (B) surface profile along the red line in (A); (C) EDX mapping; and (D) 3D projection of the sample. 


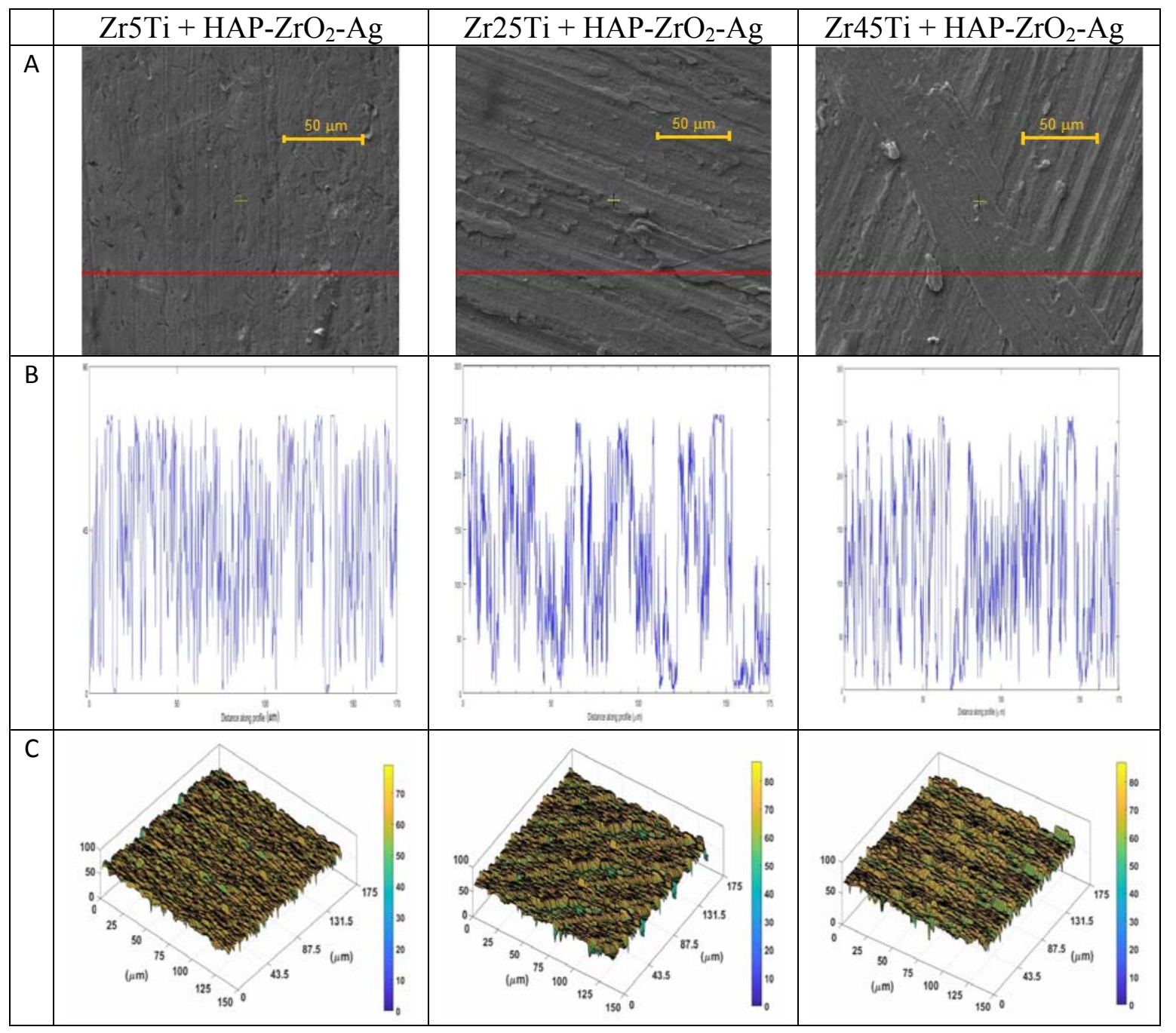

Figure 3. Morphological characterization of $\mathrm{HAP}-\mathrm{ZrO}_{2}-\mathrm{Ag}$ coated $\mathrm{ZrTi}$ implants retrieved after 1 month implantation. (A) Conventional SEM micrographs; (B) surface profile plots recorded along the red lines drawn in (A); and (C) 3D reconstructed spatial projections. 


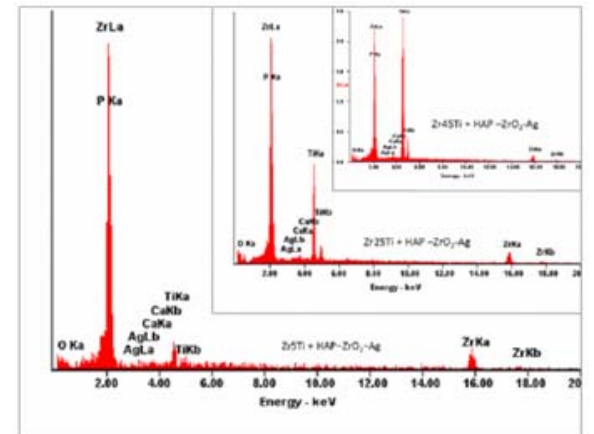

A

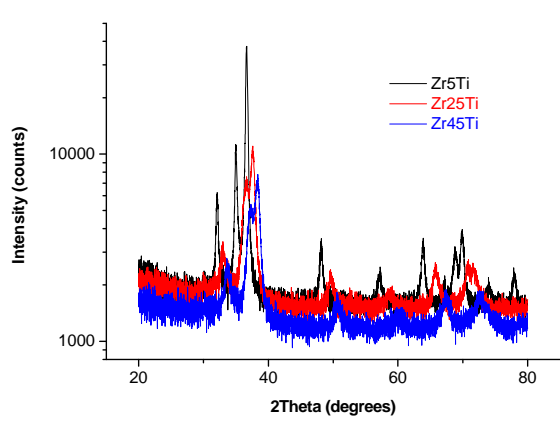

B

Figure 4. (A) EDX spectra, and (B) X-Ray diffractograms of $\mathrm{HAP}-\mathrm{ZrO}_{2}-\mathrm{Ag}$ coated ZrTi implants retrieved after implantation.
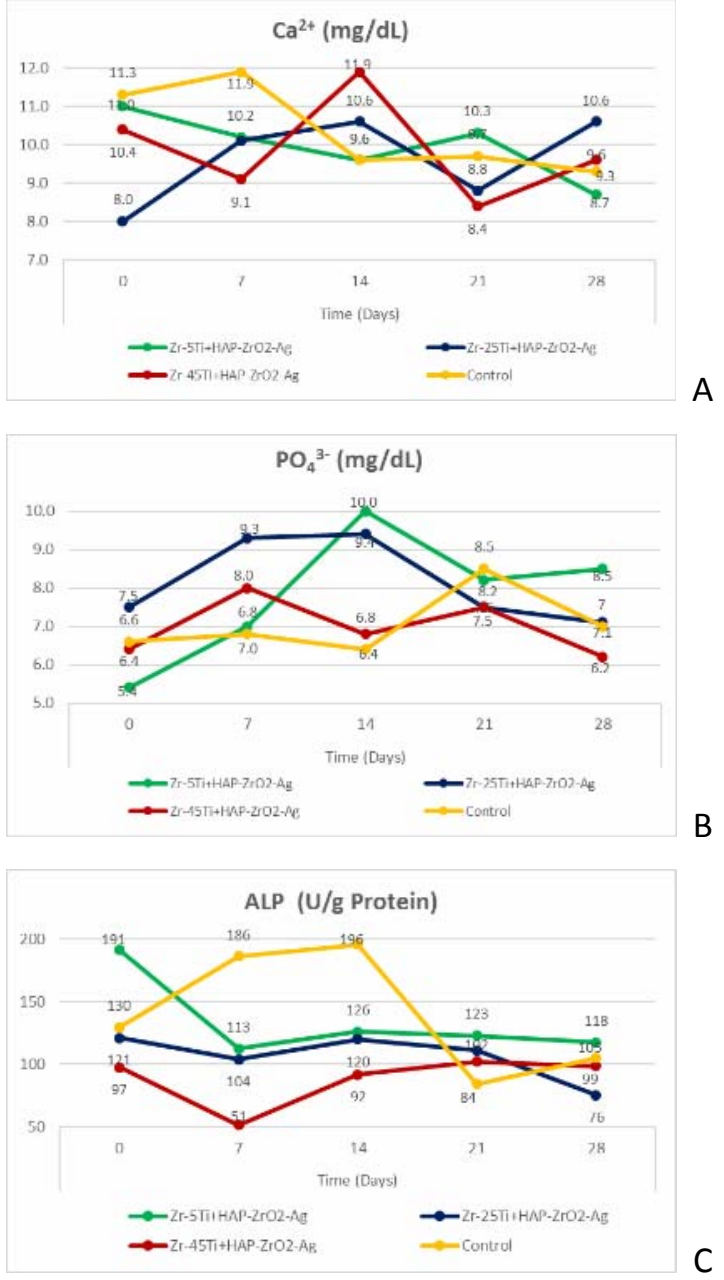

Figure 5. Dynamics of mean values of ionic calcium $\left(\mathrm{Ca}^{2+}\right)$, inorganic phosphate $\left(\mathrm{PO}_{4}{ }^{3-}\right)$, and alkaline phosphatase activity for the experimental pig models with tibial implants. 


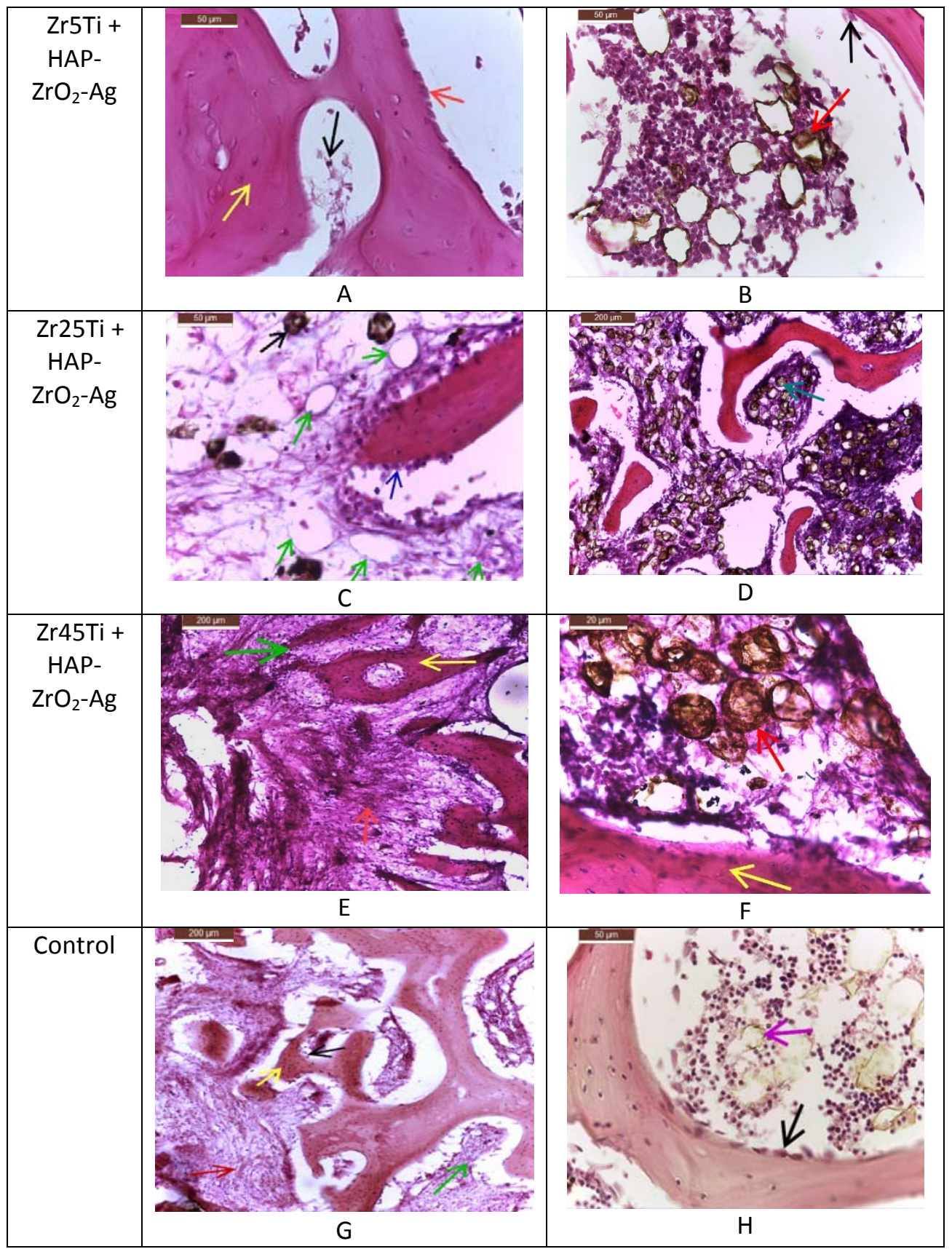

Figure 6. Morphology of the bone tissue at the contact interface with the implanted specimens. (A, B) Zr5Ti implant group: (A) The implant's proximity area $(<2500 \mu \mathrm{m})$ : aligned osteoblasts (red arrow) attached to the bone bay (yellow arrow), osteoprogenitor cells in areoles (black arrow); Col HE $\times 400$. (B) Neighborhood area $(2500-6000 \mu \mathrm{m})$ to the implant: osteoblast near the bone trachea (black arrow) and macrophages loaded with an acicular shape brown pigment (red arrow); Col HE $\times 400$. (C, D) Zr25Ti implant

group: (C) The implant's proximity area $(<2500 \mu \mathrm{m})$ : bone bay surrounded by osteoblasts on 2-3 rows (blue arrow); in the bone marrow: capillaries (green arrow) and macrophages loaded with dark particles (black arrow); Col HE $\times 400$. (D) Neighborhood 
area $(2500-6000 \mu \mathrm{m})$ of the implant: bone marrow with many macrophages loaded with an acicular shape brown pigment (green arrow); Col HE $\times 100$. (E, F) Zr45Ti implantgroup: (E) The implant's proximity area $(<2500 \mu \mathrm{m})$ : connective tissue with predominant osteoprogenitor cells (red arrow), newly formed bone tissue (yellow arrow), and osteoblasts (green arrow); Col HE $\times 100$. (F) Neighborhood area $(2500-6000 \mu \mathrm{m})$ of the implant: bone bay (yellow arrow) with osteocytes in cavities; bone marrow with many macrophages loaded with an acicular shape brown pigment (red arrow); Col HE $\times 900$. $(\mathrm{G}, \mathrm{H})$ Control group: $(\mathrm{G})$ The implant's proximity area $(<2500 \mu \mathrm{m})$ : connective tissue with predominant osteoprogenitor cells (red arrow), newly formed bone (yellow arrow) with osteoblasts around (black arrow) can be observed in the areoles; osteoprogenitor cells and reticulin fibers (green arrow); Col HE $\times 100$. (H) Neighborhood area (2500-6000 $\mu \mathrm{m}$ ) of the implant: bone bay with osteoblasts (black arrow) disposed in a single row; bone marrow low-load macrophages, colored in light brown (pink arrow), and wear pigment; Col $\mathrm{HE} \times 400$.

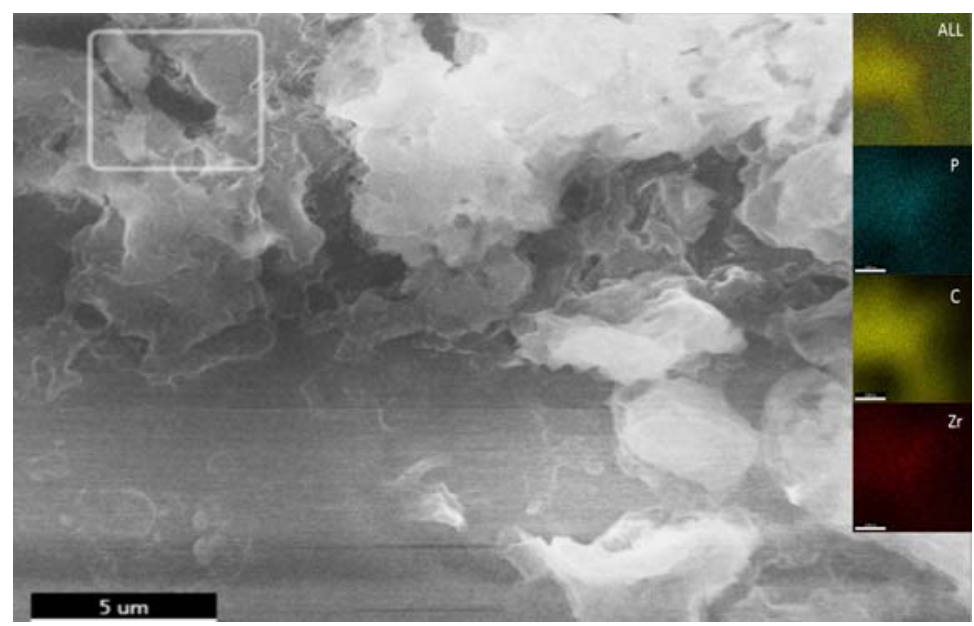

Figure 7. Elemental nanoscale mapping of the histological samples at the bone-ZrTi implant interface. 


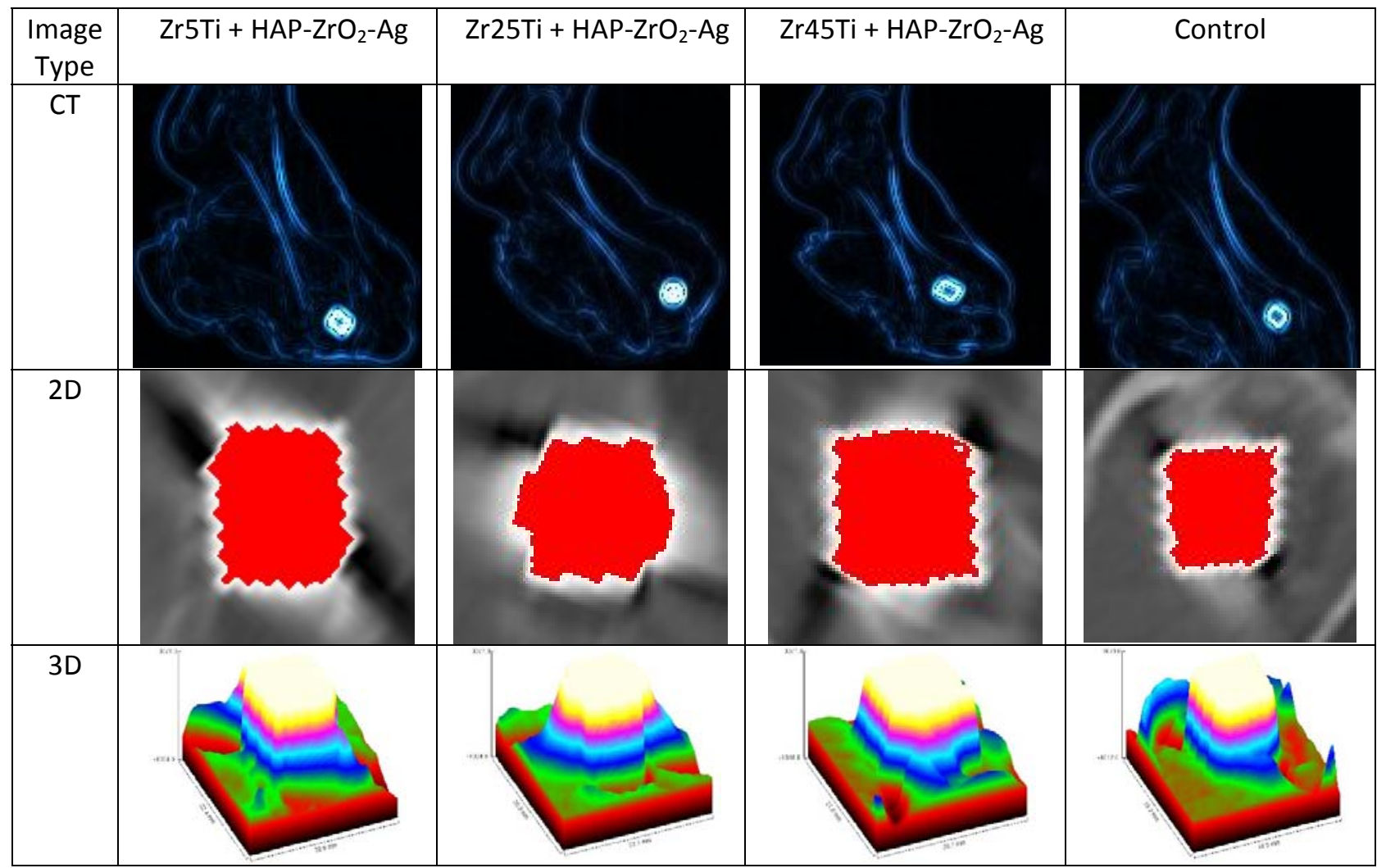

Figure 8. (A) CT, (B) 2D, and (C) 3D reconstructive images of the pig's tibiae bone with implanted specimens. 


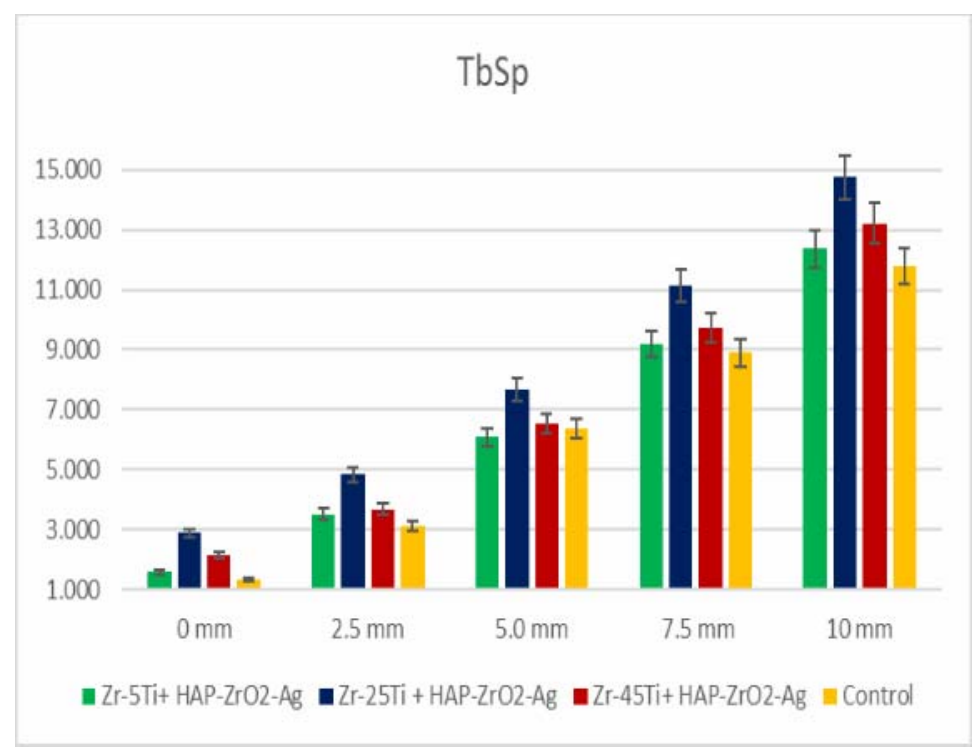

Figure 9. Variations of: (A) BV/TV ratio, (B) Tb.Th, mean, and (C) Tb.Sp mean values in pig tibia, for a rectangular region of interest, with the distance (in length and width) of $2.5 \mathrm{~mm}, 5 \mathrm{~mm}, 7.5 \mathrm{~mm}, 10 \mathrm{~mm}$ from the implant surface, respectively.

Table 1. Chemical composition of Zr-Ti alloys (wt.\%).

\begin{tabular}{|c|c|c|c|c|c|c|c|}
\hline Alloy & $\mathrm{Zr}$ & $\mathrm{Ti}$ & $\mathrm{Sn}$ & $\mathrm{Mo}$ & $\mathrm{Nb}$ & $\mathrm{Fe}$ & $\mathrm{Cr}$ \\
\hline Zr5Ti & 92.42 & 5 & 0.99 & 0.85 & 0.50 & 0.20 & 0.04 \\
\hline Zr25Ti & 72.67 & 25 & 0.81 & 0.82 & 0.45 & 0.20 & 0.05 \\
\hline Zr45Ti & 53.88 & 45 & 0.30 & 0.50 & 0.14 & 0.14 & 0.04 \\
\hline
\end{tabular}


Table 2. Surface topography main parameters of the implanted specimens.

\begin{tabular}{|l|c|c|c|c|c|c|}
\hline \multicolumn{1}{|c|}{ Sample } & $\begin{array}{c}\text { Specific } \\
\text { surface } \\
\text { pores } \\
(3 \mathrm{D})\end{array}$ & $\begin{array}{c}\text { Specific } \\
\text { surface } \\
\text { grains } \\
(3 \mathrm{D})\end{array}$ & $\begin{array}{c}\text { Average } \\
\text { pore } \\
\text { radius } \\
(\mu \mathrm{m})\end{array}$ & $\begin{array}{c}\text { Standard } \\
\text { deviation } \\
\text { of pore } \\
\text { radius } \\
(\mu \mathrm{m})\end{array}$ & $\begin{array}{c}\text { Porosity } \\
(\%)\end{array}$ & $\begin{array}{c}\mathrm{R}_{\mathrm{a}} \\
\text { Roughness } \\
(\mu \mathrm{m})\end{array}$ \\
\hline $\mathrm{Zr5Ti}+\mathrm{HAP}-\mathrm{ZrO}_{2}-\mathrm{Ag}$ & 0.055 & 0.051 & 32.721 & 19.077 & 0.482 & 3.819 \\
\hline $\begin{array}{l}\mathrm{Zr} 25 \mathrm{Ti}+\mathrm{HAP}-\mathrm{ZrO}_{2^{-}} \\
\mathrm{Ag}\end{array}$ & 0.039 & 0.043 & 39.610 & 26.110 & 0.523 & 4.699 \\
\hline $\begin{array}{l}\mathrm{Zr} 45 \mathrm{Ti}+\mathrm{HAP}-\mathrm{ZrO}_{2-} \\
\mathrm{Ag}\end{array}$ & 0.024 & 0.058 & 53.897 & 33.494 & 0.703 & 4.876 \\
\hline \multicolumn{1}{c}{ Control } & 0.014 & 0.071 & 61.78 & 60.60 & 0.829 & 8.346 \\
\hline
\end{tabular}

Table 3. Chemical analysis (wt.\%) of the implants' surfaces by EDX technique.

\begin{tabular}{|c|c|c|c|c|c|c|}
\hline \multirow[t]{2}{*}{ Group } & \multicolumn{6}{|c|}{ Element (wt.\%) } \\
\hline & $\mathrm{Zr}$ & $\mathrm{Ti}$ & $\mathrm{O}$ & $\mathrm{Ca}$ & $\mathrm{P}$ & $\mathrm{Ag}$ \\
\hline $\mathrm{Zr} 5 \mathrm{Ti}+\mathrm{HAP}-\mathrm{ZrO}_{2}-\mathrm{Ag}$ & $\begin{array}{c}77.39 \pm \\
1.83\end{array}$ & $\begin{array}{c}6.39 \pm \\
0.14\end{array}$ & $\begin{array}{c}12.53 \pm \\
0.50\end{array}$ & $\begin{array}{c}2.10 \pm \\
0.32\end{array}$ & $\begin{array}{c}0.90 \pm \\
0.39\end{array}$ & $\begin{array}{c}0.69 \pm \\
0.32\end{array}$ \\
\hline $\mathrm{Zr} 25 \mathrm{Ti}+\mathrm{HAP}-\mathrm{ZrO}_{2}-\mathrm{Ag}$ & $\begin{array}{c}57.74 \pm \\
1.67\end{array}$ & $\begin{array}{c}27.61 \pm \\
0.60\end{array}$ & $\begin{array}{c}12.60 \pm \\
1.00\end{array}$ & $\begin{array}{c}1.26 \pm \\
0.19\end{array}$ & $\begin{array}{c}0.51 \pm \\
0.36\end{array}$ & $\begin{array}{c}0.28 \pm \\
0.22\end{array}$ \\
\hline $\mathrm{Zr} 45 \mathrm{Ti}+\mathrm{HAP}-\mathrm{ZrO}_{2}-\mathrm{Ag}$ & $\begin{array}{c}39.84 \pm \\
1.41\end{array}$ & $\begin{array}{c}46.70 \pm \\
0.94\end{array}$ & $\begin{array}{c}10.27 \pm \\
1.15\end{array}$ & $\begin{array}{c}1.00 \pm \\
0.15\end{array}$ & $\begin{array}{c}1.60 \pm \\
0.28\end{array}$ & $\begin{array}{c}0.59 \pm \\
0.16\end{array}$ \\
\hline
\end{tabular}


Table 4. $\mathrm{Ag}, \mathrm{Ca}$, and $\mathrm{P}$ concentrations of the bone surface in close contact with the implanted specimens.

\begin{tabular}{|c|c|c|c|c|}
\hline \multirow{2}{*}{ Group } & \multicolumn{4}{|c|}{ Parameter } \\
\cline { 2 - 5 } & $\mathrm{Ag}(\mathrm{mg} / \mathrm{g})$ & $\mathrm{Ca}(\mathrm{mg} / \mathrm{g})$ & $\mathrm{P}(\mathrm{mg} / \mathrm{g})$ & $\mathrm{Ca} / \mathrm{P}$ \\
\hline $\mathrm{Zr5Ti}+\mathrm{HAP}_{-} \mathrm{ZrO}_{2}-\mathrm{Ag}$ & $0.072 \pm 0.006$ & $115.360 \pm 11.5$ & $58.573 \pm 6.1$ & 1.969 \\
\hline $\mathrm{Zr} 25 \mathrm{Ti}+\mathrm{HAP}-\mathrm{ZrO}_{2}-\mathrm{Ag}$ & $1.569 \pm$ & $136.065 \pm 15.7$ & $61.884 \pm 5.9$ & 2.199 \\
& $0.110^{*}$ & & & \\
\hline $\mathrm{Zr} 45 \mathrm{Ti}+\mathrm{HAP}-\mathrm{ZrO}_{2}-\mathrm{Ag}$ & $0.158 \pm 0.02$ & $146.240 \pm$ & $81.317 \pm 7.6^{*}$ & $1.798^{*}$ \\
& & $12.2^{*}$ & & \\
\hline Control & - & $127.306 \pm 12.6$ & $57.375 \pm 5.3$ & 2.219 \\
\hline
\end{tabular}

${ }^{*} p<0.05$

Table 5. Number of normal macrophages and macrophages loaded with debris adjacent to the implant surface.

\begin{tabular}{|l|c|c|}
\hline \multicolumn{1}{|c|}{ Group } & Normal Macrophages & $\begin{array}{c}\text { Macrophages loaded with } \\
\text { debris from the implant's } \\
\text { surface }\end{array}$ \\
\hline $\mathrm{Zr} 5 \mathrm{Ti}+\mathrm{HAP}-\mathrm{ZrO}{ }_{2}-\mathrm{Ag}$ & $14.0 \pm 7.1$ & $5.5 \pm 2.1$ \\
\hline $\mathrm{Zr} 25 \mathrm{Ti}+\mathrm{HAP}_{\mathrm{ZrO}}-\mathrm{Ag}$ & $16.0 \pm 1.7^{*}$ & $34.7 \pm 3.2^{*}$ \\
\hline $\mathrm{Zr} 45 \mathrm{Ti}+\mathrm{HAP}-\mathrm{ZrO}_{2}-\mathrm{Ag}$ & $11.7 \pm 1.5$ & $4.3 \pm 0.6$ \\
\hline $\mathrm{C}$ Control & $18.0 \pm 5.7^{*}$ & $33.0 \pm 7.1^{*}$ \\
\hline${ }^{*}<0.05$ & \multicolumn{2}{|l}{} \\
\hline
\end{tabular}

